$$
\text { Pontifícia }_{\text {Universidade }} \text { Católica }_{\text {do Rio de Janeiro }}
$$

Celia Elisa Alves de Magalhães

\title{
ENTÃO ME BATEU UM GRANDE FRIO NA BARRIGA. EM CENA, O PROFESSOR COORDENADOR DE INGLÊS: UM ESTUDO SOBRE IDENTIDADE E AVALIAÇÃO
}

\section{Dissertação de Mestrado}

Dissertação apresentada ao Programa de Pósgraduação em Estudos da Linguagem do Departamento de Letras da PUC-Rio como parte dos requisitos parciais para obtenção do título de Mestre em Letras/Estudos da Linguagem.

Orientador: Adriana Nogueira Accioly Nóbrega 


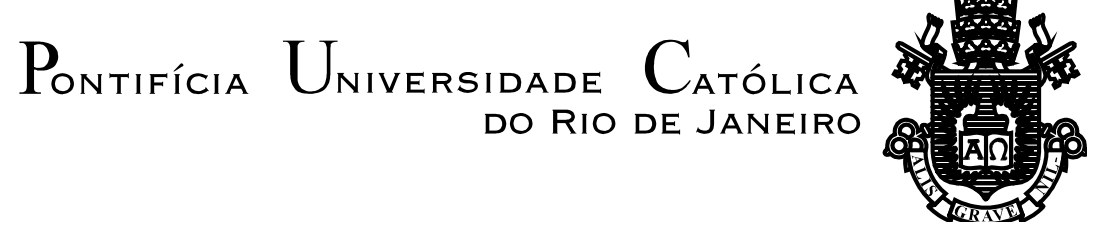

Célia Elisa Alves de Magalhães

\section{ENTÃO ME BATEU UM GRANDE FRIO NA BARRIGA. EM CENA, O PROFESSOR COORDENADOR DE INGLÊS: UM ESTUDO SOBRE IDENTIDADE E AVALIAÇÃO}

Dissertação apresentada como requisito parcial para obtenção do grau de Mestre pelo Programa de Pós-Graduação em Estudos da Linguagem do Departamento de Letras do Centro de Teologia e Ciências Humanas da PUC-Rio. Aprovada pela Comissão Examinadora abaixo assinada.

Profa. Adriana Nogueira Accioly Nóbrega

Orientadora

Departamento de Letras - PUC-Rio

Profa. Liliana Cabral Bastos

Departamento de Letras - PUC-Rio

Profa. Isabel Cristina Rangel Moraes Bezerra

UERJ

Profa. Denise Berruezo Portinari Coordenadora Setorial do Centro de Teologia e Ciências Humanas - PUC-Rio

Rio de Janeiro, 22 de março de 2013. 
Todos os direitos reservados. É proibida a reprodução total ou parcial do trabalho sem autorização da universidade, da autora e do orientador.

\section{Célia Elisa Alves de Magalhães}

Cursou a pós-graduação Lato Sensu em Língua Inglesa pela UERJ. É professora de inglês como língua estrangeira (EFL), tendo atuado também como coordenadora em uma instituição de ensino da língua inglesa. Possui diversas certificações em ensino de EFL e artigos publicados na área de Estudos da Linguagem.

Ficha Catalográfica

Magalhães, Celia Elisa Alves de

Então me bateu um grande frio na barriga. Em cena, o professor coordenador de inglês: um estudo sobre identidade e avaliação / Celia Elisa Alves de Magalhães ; orientador: Adriana Nogueira Accioly Nóbrega. - 2013.

236 f. : il. (color.) ; $30 \mathrm{~cm}$

Dissertação (mestrado)-Pontifícia Universidade Católica do Rio de Janeiro, Departamento de Letras, 2013.

Inclui bibliografia

1. Letras - Teses. 2. Professor coordenador de inglês. 3. Identidade. 4. Avaliação. 5. Prática discursiva. 6. Narrativa. I. Nóbrega, Adriana Nogueira Accioly. II. Pontifícia Universidade Católica do Rio de Janeiro. Departamento de Letras. III. Título. 
Aos meus queridos pais. 


\section{Agradecimentos}

A minha orientadora Professora Adriana Nogueira Accioly Nóbrega pelo acolhedor início desta parceria, pela competência, pelo incentivo e generosidade, pelas preciosas sugestões e pela confiança em mim depositada.

Aos participantes desta pesquisa que tão generosamente cederam seu tempo e colocaram-se à disposição da prática reflexiva que visava à elaboração deste trabalho. Sem eles, este estudo não teria sido realizado.

À PUC-Rio pela oportunidade de realizar este trabalho.

À Coordenação de Aperfeiçoamento de Pessoal de Nível Superior (CAPES) pela bolsa de estudos concedida.

A todos os meus professores de mestrado pela competência, dedicação e entusiasmo pela pesquisa.

À professora Maria das Graças Dias Pereira pelo incentivo e pela generosidade em me ceder valiosas referências.

Aos funcionários da Biblioteca da PUC e da Secretária de Letras pela gentileza e eficiência, em especial à Francisca Ferreira de Oliveira.

A todos que direta ou indiretamente contribuiram para a realização deste trabalho.

A minha mãe, pelo amor e apoio constante. 


\section{Resumo}

Magalhães, Célia Elisa Alves de; Nóbrega, Adriana Nogueira Accioly. "Então me bateu um grande frio na barriga." Em cena, o professor coordenador de inglês: Um estudo sobre identidade e avaliação. Rio de Janeiro, 2013. 236 p. Dissertação de Mestrado - Departamento de Letras, Pontifícia Universidade Católica do Rio de Janeiro.

Este estudo investiga a construção identitária do professor coordenador de inglês, com enfoque na avaliação. $\mathrm{O}$ arcabouço teórico fundamenta-se no conceito de identidade pelo viés de teorias do socioconstrucionismo (Bhabha, 1994; Bucholtz e Hall, 2003, 2005; Moita Lopes, 2002, 2003) e da Sociologia (Bauman, 2005; Giddens, 1999; Hall, 1992), concebendo a construção de identidades como um processo desenvolvido discursivamente na interação. As interações são analisadas a partir das noções de enquadre (Goffman,1974), esquemas de conhecimento (Tannen e Wallet ([1987] 2002 ), footing (Goffman, [1979] 2002), e face (Goffman, [1967] 2011). As instâncias de avaliação são abordadas na perspectiva da teoria da narrativa segundo Labov e Waletzky (1967) e Labov (1972) e na visão socioconstrucionista da narrativa como prática social (Bastos, 2005; Bruner, 1997; Cortazzi e Jim, 2001; Linde,1993; Mishler, 1999; Moita Lopes, 2003), sendo também consideradas a Teoria Sociocognitiva da Metáfora (Gibbs, 1994) e a Teoria da Avaliatividade (Martin, 2003; White, ([2001] 2012). Esta pesquisa de cunho qualitativo-interpretativo foi conduzida em uma escola da Rede de Ensino Privada do Rio de Janeiro. Além da professora pesquisadora, participaram deste trabalho quatro professores de língua inglesa bem como a professora coordenadora de inglês, a vice-diretora e o diretor da instituição. Os resultados mostram que, durante a interação, os participantes resignificam as suas interpretações a respeito das identidades do professor coordenador de inglês, que é considerado um mediador ou gerenciador de processos, situações e relacionamentos. Os dados revelam que o afeto, julgamentos e apreciações permeiam a construção identitária do professor coordenador, que também é constituída pelas relações de poder e influenciada pela identidade institucional.

\section{Palavras-chave} narrativa.

Professor coordenador de inglês; identidade; avaliação; prática discursiva; 


\section{Abstract}

Magalhães, Célia Elisa Alves de; Nóbrega, Adriana Nogueira Accioly (Advisor). "So I felt butterflies in my stomach." On stage, the Head of the English Department: A study about identity and evaluation. Rio de Janeiro, 2013. 236p. MSc. Dissertation - Departamento de Letras, Pontifícia Universidade Católica do Rio de Janeiro.

This study aims to investigate the identity construction of the Head of the English Department, with a focus on evaluation. The theoretical framework is based on the concept of identity construction according to socio constructionist (Bhabha, 1994; Bucholtz \& Hall, 2003, 2005; Moita Lopes, 2002, 2003) and sociological (Bauman, 2005; Giddens, 1999; Hall, 1992) theories that conceive identity building as a process developed in discourse during interaction. For an analysis of the interaction, the notions of frame (Goffman, 1974), knowledge schemas (Tannen \& Wallet ([1987] 2002), footing (Goffman, [1979] 2002), and face (Goffman, [1967] 2011) are considered. Evaluation is approached from the following perspectives: the labovian theory of narrative (Labov \& Waletzky,1967; Labov,1972), the socio constructionist notion of narrative as social practice (Bastos, 2005; Bruner, 1997; Cortazzi \& Jim, 2001; Linde,1993; Mishler, 1999; Moita Lopes, 2003), the Socio Cognitive Theory of Metaphore (Gibbs, 1994) and Appraisal Theory (Martin, 2003; White, ([2001] 2012). This research, which follows a qualitative-interpretative approach, was carried out at a school from the private sector in Rio de Janeiro. Apart from the teacher researcher, four English teachers participated in this work as well as the Head of the English Department and the principal and vice-principal of the institution. Results show that during the interaction participants re-signify their interpretations with respect to the identities of the Head of the English Department, who is regarded as a mediator or manager of processes, situations and relationships. The data reveals that affection, judgment and appreciation permeate the Head of the English Department identity construction, which is also constituted by power relations and influenced by the institutional identity.

\section{Keywords} narrative.

Head of the English Department; identity; evaluation; discourse practice; 


\section{Sumário}

1. O começo de tudo: a motivação 13

2. O professor coordenador 19

2.1. O professor coordenador: reflexo do contexto político-social 19

2.1.1. O professor coordenador: contextualização histórica 21

2.1.2. As atribuições do professor coordenador a partir de $1980 \quad 24$

2.1.3. A formação do professor coordenador 27

3. O processo identitário 31

3.1. O conceito de identidade 31

3.1.1. Identidades fragmentadas, múltiplas e contraditórias 31

3.1.2. Identidade: fenômeno sociocultural discursivo 33

3.2. Identidades em interação: negociação e apresentação social 38

3.2.1. Enquadres, esquemas e footings: construindo e entendendo o self 40

3.2.2. Face: elemento do evento de fala 43

4. Prática discursiva e avaliação: faces da construção identitária 46

4.1. Prática discursiva e construção identitária 47

4.2. Tecendo elos: avaliação, identidade e prática discursiva narrativa 49

4.3. Avaliação e narrativa 50

4.3.1. Narrativa na perspectiva laboviana 52

4.3.1.1. Avaliação na perspectiva laboviana 53

4.3.2. Narrativa na perspectiva socioconstrucionista $\quad 55$

4.3.2.1. Avaliação na perspectiva socioconstrucionista 60

4.3.3. Avaliação na linguagem figurada 63

4.3.4. A Teoria da Avaliatividade 67

4.3.4.1. O sistema da ATITUDE 68

4.3.5. Avaliação: entrelaçando conceitos 71

5. Aspectos Metodológicos 74

5.1. Natureza da pesquisa 74

5.2. A entrevista como procedimento metodológico 75

5.2.1. A entrevista de pesquisa qualitativa semiestruturada 77

$\begin{array}{lll}\text { 5.2.2. } & \text { Os papéis dos participantes na entrevista } & 79\end{array}$ 
5.2.3. As relações de poder na entrevista 81

5.3. O contexto de pesquisa 83

5.3.1. O perfil acadêmico e profissional dos participantes $\quad 85$

5.4. A construção dos dados 87

5.4.1. A entrevista com os docentes e com a coordenação 89

5.4.2. A entrevista com a diretoria: a voz da instituição 93

5.4.3. Entrevista com a professora Ana: a troca de posições 94

5.5. A transcrição dos dados 95

5.6. Critérios de análise 96

6. Análise dos dados: recortes discursivos de uma trajetória identitária 99

6.1. O convite para tornar-se professor coordenador 100

6.1.1. "Então me bateu um grande frio na barriga" 101

6.1.2. "deixa eu criar mais experiência" 104

6.1.3. "Entrei de gaiato no navio" 107

6.1.4. "te tira daquela zona de conforto" 112

6.2. As atribuições do professor coordenador de inglês 116

6.2.1. A visão dos professores 117

6.2.1.1. Um ponto de apoio ou um sargento? 118

6.2.1.2. O orientador ou motivador do corpo docente 123

6.2.2. A visão do coordenador 126

6.2.2.1 "e eu achei que era pra ser demitida" 127

6.2.2.2. "Agora o nosso papo vai ser de cobrança" 128

6.2.2.3. "mas a gente não trocava figurinha" 133

6.2.2.4. "A gente apaga incêndio" 136

6.2.2.5. "é muito bom poder organizar" 139

6.2.3. A visão da Direção 141

6.2.3.1. "A arte realmente de administrar" 141

6.2.3.2. "você tem que ter respaldo dos seus coordenados" 145

$\begin{array}{lll}\text { 6.3. A formação do professor coordenador } & 147\end{array}$

6.3.1. "foi o melhor curso que eu fiz na minha vida" 147

6.4. O desligamento da função de professor coordenador 149

6.4.1. "Ah, você não, não mostrou pro povo que você é virtuoso" 150

6.5. A vantagem em "ser"/"estar" coordenador 154

6.5.1. "Aí a pergunta é, pra que, né?" 154

6.6. Questões de pesquisa: momento de reflexão 157

$\begin{array}{ll}\text { 7. Considerações finais } & 174\end{array}$

$\begin{array}{lll}\text { 8. } & \text { Referências } & 179\end{array}$

$\begin{array}{lll}\text { 9. Anexos } & 190\end{array}$ 


\section{Índice de figuras}

$\begin{array}{lll}\text { Figura } 1 \text { - } & \text { O sistema da ATITUTE. } & 71\end{array}$

Figura 2 - Posição hierárquica dos participantes no Colégio Brasil.

Figura 3 - Esquema representativo da primeira fase de entrevista.

Figura 4 - Esquema representativo da segunda fase de entrevistas.

Figura 5 - Esquema representativo da terceira fase de entrevistas com os professores de inglês.

Figura 6 - Esquema representativo da terceira fase de entrevistas com a coordenadora de inglês.

92

Figura 7 - Esquema representativo da entrevista com a direção.

Figura 8 - Esquema representativo da entrevista com a professora coordenadora de inglês indicada para o ano de 2013.

Figura 9 - Quadro interacional (Baseado em Rodrigues e Azevedo, 2010, p. 5).

Figura 10 - O processo de formação do professor coordenador de inglês (Adaptado de Domingues, 2009, p. 87)

Figura 11- Quadro interacional (Baseado em Rodrigues e Azevedo, 2010, p. 5).

Figura 12 - Quadro interacional (Baseado em Rodrigues e Azevedo, 2010, p. 5).

Figura 13- Esquema representativo do imbricamento entre práticas e processos discursivos, práticas cotidianas e formação inicial e contínua.

Figura 14- Identidades do professor coordenador de inglês emergentes no discurso dos participantes. 


\section{Índice de quadros}

Quadro 1 - Contrutos teóricos apresentados no capítulo 4

Quadro 2 - Perfil acadêmico dos participantes

(Idades entre 29-48 anos).

Quadro 3 - Perfil profissional dos participantes (Idades entre 29-48 anos).

Quadro 4 - Proteção à face como eixo da constituição identitária.

Quadro 5 - Trechos avaliativos emergentes nas narrativas dos participantes.

Quadro 6 - Instâncias de avaliações situadas nas dimensões do AFETO, JULGAMENTO e APRECIAÇÃO.

Quadro 7 - Instâncias de avaliação através da linguagem figurada. 
Há um tempo em que é preciso abandonar as roupas usadas Que já têm a forma do nosso corpo E esquecer os nossos caminhos que nos levam sempre aos mesmos lugares

É o tempo da travessia E se não ousarmos fazê-la Teremos ficado para sempre À margem de nós mesmos. 